\title{
Probing protein conformation destabilization in sterile liquid formulations through the formation of 3,4- dihydroxyphenylalanine.
}

Olivier Mozziconacci ${ }^{1}$, Natalia Subelzu${ }^{2}$, Christian Schöneich ${ }^{2}$, Yong Liu ${ }^{1}$, Andreas Abend ${ }^{1}$, W. Peter Wuelfing ${ }^{1}$

${ }^{1}$ Merck \& Co., Inc., Rahway, NJ, USA

${ }^{2}$ Department of Pharmaceutical Chemistry, The University of Kansas, KS

Corresponding author: Olivier Mozziconacci (olivier.mozziconacci@merck.com) 


\section{SUPPLEMENTARY INFORMATION}

\section{Primary SeQuences OF IgG2 AND IgG4}

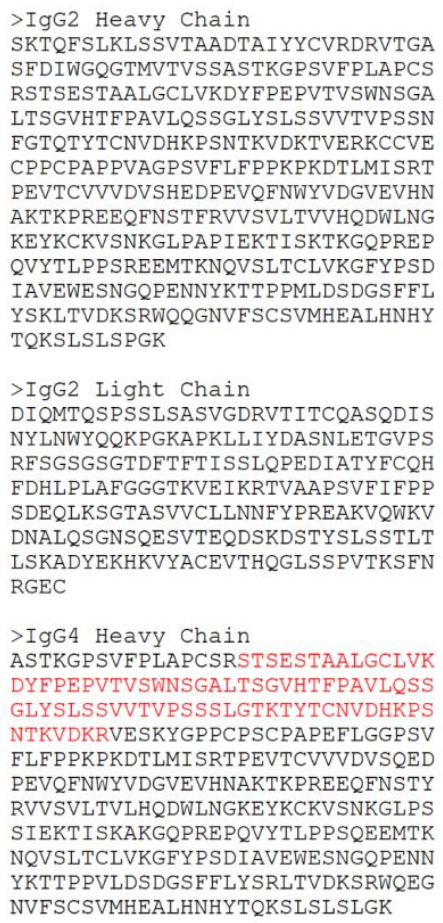

Figure S. 1: Primary sequences of IgG2 and IgG4. Peptide 20 is highlighted in red. 


\section{MS/MS FRAGMENTATION OF PEPTIDE 20 OF IGG4}

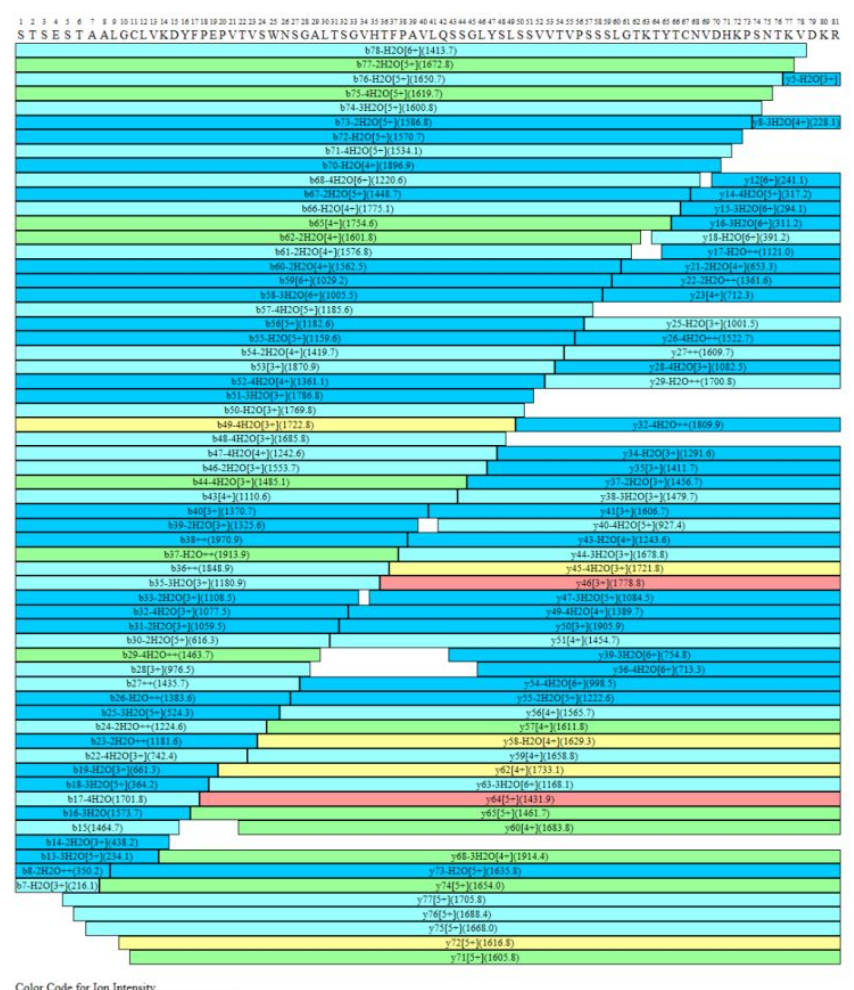

Color Code for lon intentivis

Figure S. 2: ETD/HCD MS/MS fragmentation of peptide 20 from IgG4. The intensities of the $b$ and y fragment ions are color coded. Cysteines are derivatized with iodoacetamide and appear as cysteamides. Only b and y fragment ions are reported. 


\section{ABS DERIVATIZED TYROSINE STRUCTURES}<smiles>NCc1ccc(S(=O)(=O)O)cc1</smiles>

ABS

Exact Mass: 187.03<smiles>CCNC(=O)C(C)Cc1ccc(O)cc1</smiles><smiles>CC(C)NC(=O)Cc1ccc(O)c(O)c1</smiles>

\section{DOPA}

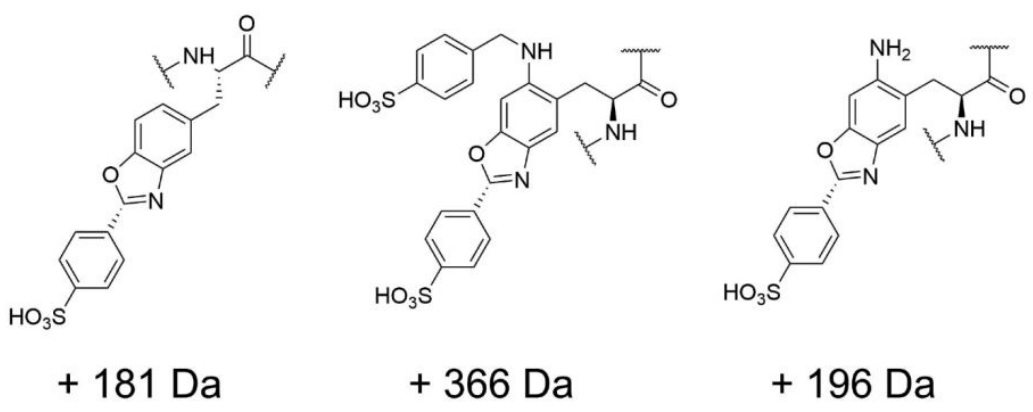

Figure S. 3: Chemical structures of ABS, Tyrosine, DOPA, and the ABS derivatized tyrosine structures. Delta of mass of 181 Da, $196 \mathrm{Da}$, and $366 \mathrm{Da}$ were taken into account during the MS/MS search of ABS derivatized tyrosine-containing peptides. 


\section{EXAMPLE OF MS/MS FRAGMENTATION OF ABS TAGGED TYR RESIDUES AND OXIDIZED PEPTIDE 20}

\section{OF IGG4}

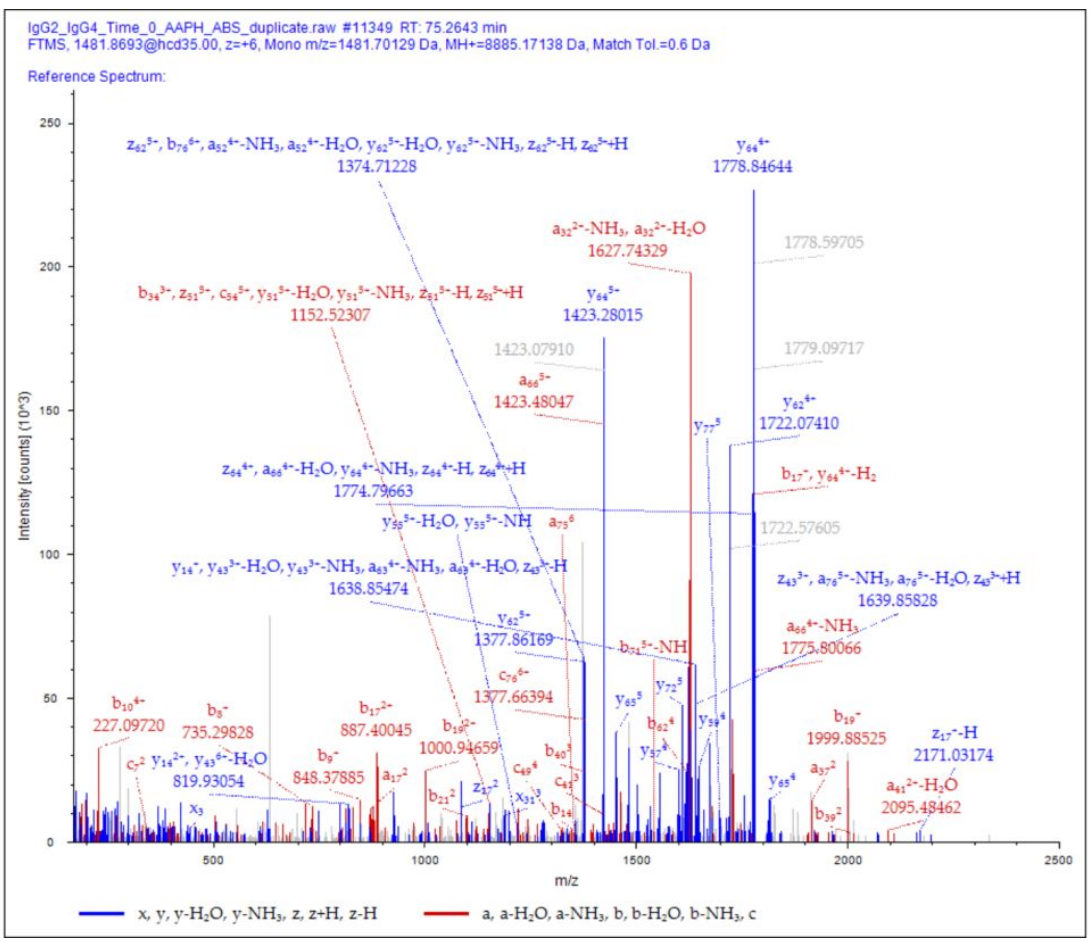

Figure S. 4: HCD MS/MS fragmentation of an ABS tagged oxidized peptide 20 from IgG4. Cysteines are derivatized with iodoacetamide and appear as cysteamides. F53 is hydroxylated ( +16 Da), Y63 is an amino tyrosine ABS tagged ( +196 Da), Y81 is ABS tagged ( $+181 \mathrm{Da}$ ), and N84 is deamidated. One letter amino acid code, F: phenylalanine, Y: tyrosine, $N$ : asparagine. 


\section{FörSter Resonance Energy TRANSFer assay (FRET): Optimization OF THE NUMber OF}

\section{FLUORESCENT DYE MOLECULE ATTACHED TO THE PROTEIN}

Protein $(2 \mathrm{mg} / \mathrm{mL})$ was purified from its original formulation using Amicon filter equipped with a cut-off membrane of $50 \mathrm{kDa}$. Protein was reconstituted in ammonium acetate pH $5.5(100 \mathrm{mM})$. Reconstituted protein in ammonium acetate was washed through the Amicon membrane three times. Protein was derivatized with the fluorescent dye Dylight-488 (or Dylight-596). The latter was performed by reconstituting first the protein in $4 \mathrm{~mL}$ of either buffer A or buffer $\mathrm{B}$, respectively. Two reaction buffers (A and B) were prepared. Buffer A consisted of PBS solution at pH 7.4. Buffer B consisted of a solution of tetraborate $(20 \mathrm{mM})$ prepared in PBS solution at pH 8.2. To label the protein with Dylight-488, the protein was reconstituted in buffer A. In contrary, to label the protein with Dylight-596, the protein was reconstituted in buffer B. $25 \mu g$ of Dylight-488 or Dylight-596 were reconstituted in $20 \mu \mathrm{L}$ of N,N-dimethylformamide (DMF) and vortex for 1 minute. Solutions of Dylight-488 and Dylight-596 reconstituted in DMF were diluted in $500 \mu L$ of buffer A and B, respectively. Protein reconstituted in buffer A (or B) was mixed with $400 \mu L$ of the Dylight488 solution (or the Dylight-596 solution). Derivatization reaction of the protein with the dye molecule was carried out at $37^{\circ} \mathrm{C}$ in the dark under a gentle agitation of $250 \mathrm{rpm}$ for 90 minutes. The yields of derivatized proteins with the fluorescent dyes were monitored by mass spectrometry. Intact protein mass spectrometry analysis was performed to ensure that the ratio of derivatizedprotein/protein (with one dye molecule per protein) was between 40-50\%. Derivatized protein was subjected to proteolytic digestion reaction in order to identify the position of the derivatized Lys residues. By limiting the derivatization of the protein to one dye per protein, only Lys-244 was labeled (Figure S. 5). Lys-244 is located in the heavy chain in the hinge region of mAb. 

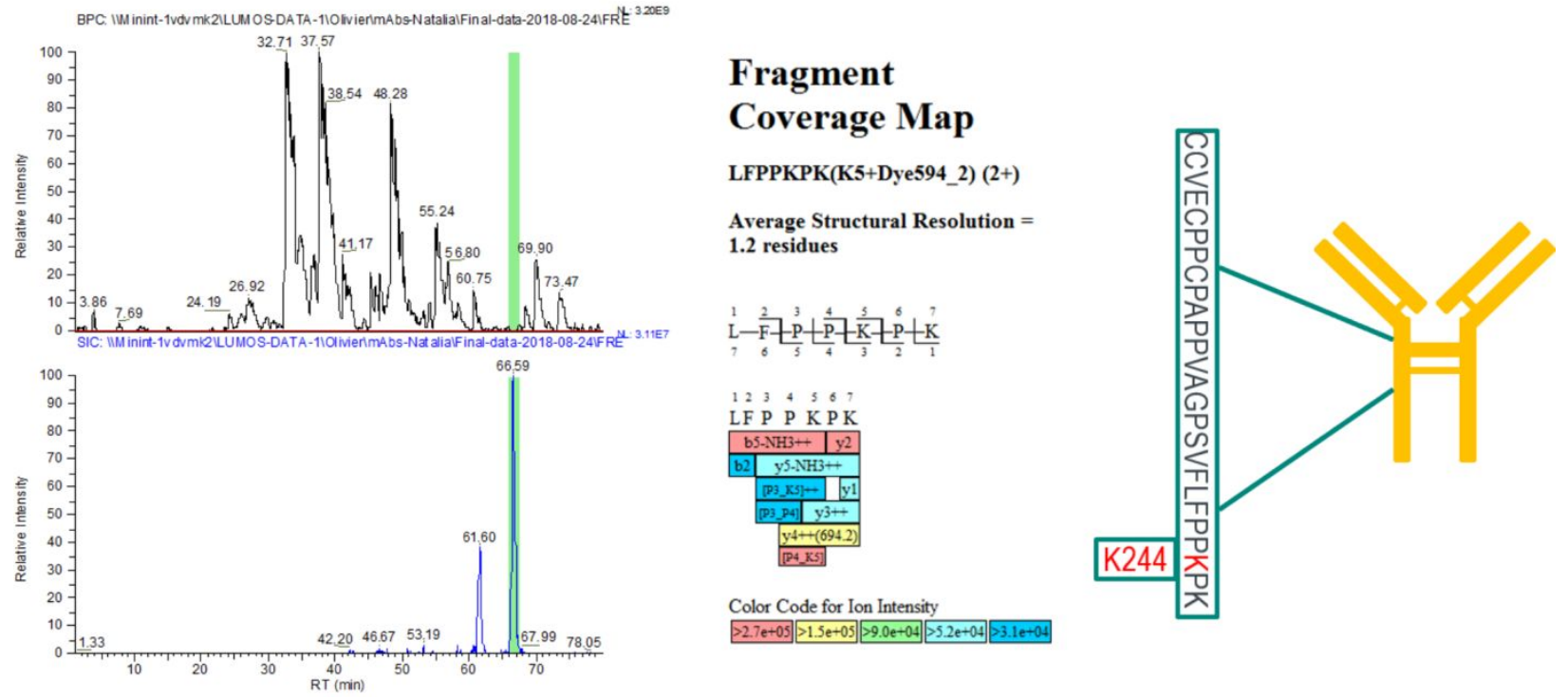

Figure S. 5: Identification of the Lys residue derivatized with Dylight-488 or Dylight-596 for FRET analyses. 